\title{
Organisational Learning for and with VUCA: Learning Leadership Revisited.
}

\author{
Elena P. Antonacopoulou \\ University of Liverpool/Management School - United Kingdom \\ e.antonacopoulou@liverpool.ac.uk
}

\begin{abstract}
For over a decade, we have not seen new and exciting developments in Organisational and Management learning theory and practice and we remain beset by the orientation towards knowledge acquisition and behavioural change as the means of accounting for the impact of learning. In this paper we consider both a new theoretical perspective and approach to learning across levels - individual, group, organisation - in an effort to pave the way for the next phase of learning research and practice relevant for the $21^{\text {st }}$ Century. Recognising Volatility, Uncertainty, Complexity and Ambiguity (VUCA) as the conditions that mirror the rhythm of the $21^{\text {st }}$ Century is one thing. Developing new ways of knowing and acting in order to address these conditions is another matter altogether. This paper provides a response to this call for addressing the VUCA conditions with a VUCA approach to learning. Building on recent calls for Learning Leadership with virtue we elaborate the importance of Leadership in $21^{\text {st }}$ Century Management and Organisational Learning and explicate the need for Courage, Commitment, Confidence and Curiosity as integral to VUCA learning. VUCA Learning Leadership promotes: learning to feel safe being Vulnerable; learning to remain Unnerved by the unknown, learning to demonstrate Candour and learning to experience Awakening. These dimensions form an extension of earlier focus in organisational and management learning on socio-materiality and account for sensoriality as a foundation for the 'New Learning Organisation'.
\end{abstract}

Keywords: VUCA, organisational learning, sensoriality, learning organisation 
There are hundreds of books on learning and yet the debate in the learning field be it infused by scholarly and practical perspectives can best be characterised as being in a state of inertia. For over a decade we have not seen new and exciting developments in learning theory and practice and we remain beset by the orientation towards knowledge acquisition and behavioural change as the means of accounting for the impact of learning. The intention at the onset is to avoid writing another paper talking about why learning is important, and instead to focus on how to foster learning that can make a difference in navigating the unknown when Volatility, Uncertainty, Complexity and Ambiguity (VUCA, Bennett \& Lemoine, 2014) mirror the everyday reality of the $21^{\text {st }}$ Century.

By adopting a non-traditional orientation to learning practice recognising that it is about the experience of learning (Antonacopoulou, 2014) the struggle it entails and the need to foster confidence in learning (Taylor, 2015) the priority is to realise the impact of learning, where ImpAct is equivalent to 'IMProving ACTion' (Antonacopoulou, 2010a) restoring the ethos of leadership by cultivating character and conscience and not only competence (Crossan et al., 2017; Havard, 2014). Such a focus is less concerned with promoting problem solving through prescriptive solutions and instead, encourages exercising reflexive critique (Antonacopoulou, 2010b). Reflexive critique is integral to the practical judgements (phronesis) that define the decision to act and to what ends.

Phronesis, is about the knowledge that defines the standards people in organisations seek to reach as they strive to conduct their practices better and better in response to a range of forces (social, political, environmental) creating paradoxes, tensions, dilemmas that influence their choices. This is demonstrated by Shotter and Tsoukas' (2014a, 2014b) accounts of how practitioners contemplate and rigorously assess how to act to avoid consequences that are damaging to themselves and others. Phronesis understood as a reflection of some deeper engagement with everyday life, highlights the meanings attributed to lived experiences, and engages both cognitions and emotions in constructing such meanings. In line with the way sensemaking (Weick, 2010; Maitlis \& Christiansen, 2014) has been understood, the capacity for phronesis signals that sensemaking exposes the space in-between emotions and cognitions, which essentially puts the senses back into sensemaking (Antonacopoulou, 2017).

The focus on multi-sensory experiences (seeing, hearing, smelling, touching, tasting) mark an emplacement that extends beyond what is taken as a context of immediate action (Pink, 2011). The paradigm of emplacement expands previous accounts of making 
sense that focus on enactment and embodiment and introduces sensoriality as a way of knowing and acting that places learning as a constantly changing event involving the constellation and entanglement of previously unrelated processes (Ingold, 2000) in the midst of acting. This paradigm goes beyond 'formativeness' that Gherardi (2015) suggests and elaborates sensoriality as part of practising as a leap of faith (Antonacopoulou, 2008; 2015). Adopting a 'strong' process perspective (Langley \& Tsoukas, 2016) in conceptualising sensoriality, embraces 'not-knowing the outcome' and 'changing without knowing the direction'. In this respect, learning as a process of becoming (Clegg et al., 2005) signals practising as integral to the individual and collective growth, learning can afford. Practising will be elaborated as a critical aspect of the process of maturation, itself an issue that has formed the foundation of earlier learning theories and one that remains insufficiently understood.

The paper is organised in three main sections. We elaborate after the introduction, the centrality of learning in everyday life to explicate why the VUCA conditions of the $21^{\text {st }}$ Century call for new modes of learning that embrace crisis. We present in the second section recent developments in learning theory promoting a sensuous orientation and explicate why central to practising is learning to feel safe being Vulnerable; learning to remain Unnerved by the unknown, learning to demonstrate Candour and learning to experience Awakening. In the third section we explicate the impact of Arts-Based Methods and Interventions in realising the impact of VUCA and explain VUCA Learning Leadership as an integral dimension of the 'New Learning Organisation' promoting sensuousness when navigating the unknown. We conclude with a review of the implications of the New Learning Organisation for the kinds of interventions that can support not only individual and organisational learning but also collective leadership development.

\section{Learning: Living, Working and Organizing in VUCA}

This multilevel change orientation at the heart of organisational learning, founded on humanistic and democratic principles calls for social complexity to be engaged with openness for the variation in learning practices that would be supported (Antonacopoulou, 2006; Antonacopoulou \& Chiva, 2007). This means that learning in organisations by individuals and communities can take place in whole variety of ways and must not be limited to either/or options (e.g. formal and informal modes of learning). Instead, embracing the 
whole phasm (array) of possibilities, calls for fostering simultaneously individual and collective learning, that mobilises collective energy to be more fully engaged.

Despite the advancements in Action Learning/science interventions (Argyris et al., 1985; Greenwood \& Levin, 2007; Coghlan \& Branning, 2014) the cycles of action that seek to bring about individual and organization transformation do not explicate fully how the capacity for phronesis emergences as an integral aspect of the learning process. This would suggest that comprehensively investigating organisational and human behaviour and attending to the properties and characteristics of a formal organisation and the ways individuals respond to the theories of action, may not fully explain the dynamics of the learning process (Crossan et al. 2011).

More recent developments acknowledging how people and materiality relate to each other and how organizational life is increasingly shaped by various material elements, such as technology, physical spaces, and artefacts, (e.g. Carlile et al., 2013; Orlikowski and Scott, 2008) acknowledges the socio-material entanglement shaping learning processes. It does not explain however, how practical judgement guides the modes of acting to steer the focus on serving the common good. There is a need to understand the learning process from a new place from which judgements, intentions, actions and their impact emanate.

If such a place were the common good offers an enhanced appreciation of the role of social practices and other collectively accomplished activities in organisations. Organizational Learning from the perspective of how social practices and activities support ways of knowing and learning (Casey, 2005; Gherardi, 2015) minimizes the role of the social world implicitly suggesting individuals as autonomous agents, capable of and generally expected to behave differently if learning has occurred.

That said, there is an issue that merits explicating and that is the 'lack of maturity' among people who make the organisation placed in different levels of the hierarchy and with different levels of power to take action. This has been the foundation of Argyris' $(1957 ; 2003)$ contribution as the 'father of Organisational Learning' (Antonacopoulou, 2004; Fulmer \& Keys, 1998). Whilst much of Argyris' work has received as much praise as it did criticism as to whether the models of action can be addressed adequately through the modes of single and double loop learning he promoted, the lack of maturity is a more fundamental aspect of his work that has not received the elaboration nor recognition it deserves. By seeking to understand individual learners first Argyris' two theories of action; 'Model I' and 'Model II' drew attention to the relationship between governing variables, action strategies and 
consequences. The 'inner-contradictions' and 'self-defeating' actions signal the complexity that people create that they then try to resolve. By scrutinising the effects of strict organisational configurations, control mechanisms and management absorbed by production and profit goals, Argyris redefined classical conceptions of organisations. In doing so, he sought through organisational learning to guide management to better explore a symbiotic relationship between individual and collective learning and in this paper we put forward the proposition that in doing so, he also sought to highlight the importance of serving the common good (McIntyre, 1985). This offers the scope for learning to form the energy force for freedom of expression grounded on self-actualisation that can be supported through team learning, shared vision and strategy adaptation capabilities that Senge's (2014) 'learning organisation' also promoted.

The compelling message of this paper, is to invite a fresh look at the strategic role of learning across individual, group and organisational levels and its impact especially under conditions of Volatility, Uncertainty, Complexity and Ambiguity (VUCA) mirroring the rhythm of the $21^{\text {st }}$ Century (Bennett \& Lemoine, 2014). VUCA explicates further why crisis is endemic to organisational life, but also why crisis is critical to learning. It also elaborates that learning is integral to crisis not as a punctuated process occurring before, during or after crisis. Whether crisis is endogenously driven due to mistakes and failures, exogenously engendered by environmental, social, economic or political forces that may be considered as rare or critical events or catastrophes, crisis entails the unknown and unknowable which shape the way learning and crisis are experienced. This perspective is central to a mode of learning that Antonacopoulou and Sheaffer (2014) refer to as Learning in Crisis (LiC).

Learning in Crisis is a mode of re-learning - learning afresh, learning differently emphasises practising, to develop new understanding, questioning current practices, experimenting with existing knowledge to develop improvements in actions, negotiating emotions, attitudes and behaviours in responding to political forces shaping the experience of learning (Antonacopoulou, 2014). This orientation towards re-learning is in sharp contrast to previous conceptualisations, which present unlearning in relation to organisational memory and the transfer of knowledge which often assumes either forgetting or discarding old knowledge in favour for new knowledge (Hedberg, 1981) as it does not fully explicate the most fundamental aspects of the experience of learning - crisis.

Crisis in this analysis and in relation to learning is used in the double meaning of the word from the Greek krisis - where the meaning of the word is not limited to circumstances 
of emergency and disaster. Crisis/Krisis also refers to tensions that call for practical judgments, exercising critique, reflexivity, which would inform decisions reached and actions taken (Antonacopoulou \& Sheaffer, 2014). In this vein, LiC is not only an emergence of the ongoing practising. It is also an emergency (crisis) when learning engenders conditions where judgments have to be made in response to the tensions experienced. This perspective challenges key assumptions that underline the debate on learning from failure (and success) and offers new insights to explain why failure to learn is an endemic organisational challenge.

In this paper we build on this mode of learning - Learning in Crisis - to elaborate a process of learning - across levels - for individuals, groups and organisations - that redresses the centrality of learning in living, working and organising in VUCA conditions. It introduces a way of understanding learning, crisis and their relationship as a dynamic process of practising. Practising defined as 'deliberate, habitual and spontaneous repetition' (Antonacopoulou 2008: 224), reflects what happens when re-hearsing, re-viewing, refining, and changing actions whilst forming judgements. Focusing on practising provides an account of how learning practices are invented and reinvented. This perspective finds support in ideas of "formativeness" (Pareyson, 1960) and is also consistent with the dynamics of everyday life and how it changes (Shove et al., 2012). Such dynamism is not simply the performative recursiveness reflected in habitual behaviour (Bourdieu, 1990), but the reconfigurations resulting from the emergence when practising. Practising activates new possibilities by re-turning to re-view, reflect and reflexively critique actions and the ways of knowing that inform it in a dynamic process of movement. As part of such movement 'the environment', 'events' or 'critical moments' where choices are made reflect the social, material and environmental conditions shaping the capacity for phronesis (Antonacopoulou, 2017). A focus on practising promotes a recognition of both the materiality and sensoriality of learning. It calls for going beyond action, activities and interactions between social actors to also account for sensing and designing courses of actions to serve the common good.

\section{Learning with a difference: Sensoriality}

Sensuousness as a way of knowing and acting has been recognised in previous accounts and references to 'sensible knowing' (Strati, 2007), 'sensuous knowing', (Gherardi, 2015), 
'sensory knowing' (Panayiotou, 2017; Springborg, 2018) all of which emphasise the role of the senses as integral to perceiving, judging and acting. These accounts however, predominantly focus on enactment and embodiment of the senses. They do not recognise the role of the senses in forming the sensations that support navigating the unknown.

Drawing the focus closer to the sensations that contribute to the judgements that inform the actions taken goes beyond stimulus and response as the foundations of the learning process. This marks a significant advancement in future organisational learning research, because it recognises that learning as part of living, working and organizing it not only about making sense of everyday experiences including the dilemmas and paradoxes that form part of everyday practice through enactment and embodiment. It will be argued that it is also a case of emplacement where the multi-sensory experiences (seeing, hearing, smelling, touching, tasting) create a sensoriality that also affects actions and judgements.

Sensoriality, as Mearleu-Ponty (1962: 4) explained in his analysis of perception, identifies sensations that reveal "qualities of objects" that in turn place our experiences in unbounded zones of possibility. We contribute to advancing sensoriality and make the case for emplacement as offering a powerful way of capturing the balance between habitual and creative action integral to practising. We argue for emplacement as a way to account for duration and the seizing of moments which draws attention to the role of sensory forces integral to learning in living, working and organizing.

The emergent paradigm of 'emplacement' (Pink, 2011) draws attention to the role of sensory forces that impact the political and ideological agendas and power relation which remain integral to judgement and associated actions. Emplacement is introduced here to extend previous references to enactment and embodiment (Ropo et al., 2015) and to show more clearly that when combined they provide a more comprehensive account of how and why learning practices are performed in the ways they do. Emplacement is valuable in this analysis, because of the centrality it places on the choices that inform such action, especially when it serves the common good. Emplacement accounts for the ways of moving beyond context in time and space to arrest the seizing of moments which define action as part of everyday life.

The ontology of emplacement gives voice to the place of multiplicity in possibility in everyday life (Serres, 1995) where subjects, objects, ideas, images, discourse and practices intertwine. Such a place is not merely a (physical) topos where actions are taken based the possibilities embedded in the connections formed. Instead, emplacement is a positioning, a 
vantage point, a placement from which 'disclosure' is possible (Spinosa et al., 2007) enabling re-viewing and re-vising the ways actions are formed and transformed every time they are performed. Disclosure in this sense reflects how practising unveils possibilities, when people reflect, refine and extend established ways of doing things. This process reflects the sensibility, sensitivity and sentience that enables the detection of small perturbations, before they evolve to a full blown crisis or error. It supports sensing the anomalies and disharmony between what is done and what needs to be done. It expresses the sensuous interrelationships between body, mind, materiality and environment to form sensoriality.

This perspective forms the core of the work of the GNOSIS 2020 Network that brings together scholars across disciplines, artists and professionals across the professions to advance new and innovative modes of learning. The work of the network, featured in two edited book volumes marks a new chapter in organisational and management research through a new theory of learning - Sensuous Learning (Antonacopoulou \& Taylor, 2018a; 2018b). The two volumes present the cutting edge Arts-based Methods and Arts-Based Interventions and the ways the facilitate Sensuous Learning, as well as the impacts of such learning. Arts-Based Methods and Artistic Interventions are elaborated as the means of advancing Sensuous Learning, not only because they adopt a non-traditional, 'presentational' way of knowing that "provides relatively direct access to our felt experience and draw upon our emotional connection to our self, others, and our experience" as Taylor \& Ladkin (2009: 56) suggest. Arts-Based Interventions liberate aesthetic, intellectual and emotional engagement and promote a mode of learning that emphasizes practising (Romanowka et al., 2013; Berthoin Antal, 2014; Berthoin Antal et al., 2018). The emphasis on practising is a critical condition for the kind of learning that cultivates character and conscience and not only the development of skills and competence (Antonacopoulou, 2018a).

Sensuous Learning has been defined as that learning which aligns cognitions, emotions and intuitive insights by fostering critique such that the complex - symplegma of emerging sensations that inspires acting, reacting and conducting one's practice with freedom of choice. Sensuous Learning is another form of drawing inferences especially when VUCA conditions call for practical judgement beyond inductive and deductive reasoning. Sensuous Learning supports abducting the essence of the issue at hand by aligning sensibility, sensitivity and sentience in making sense of the issue that calls for action (Antonacopoulou, 2018a). Sensuous Learning creates the foundation for feeling safe 
being vulnerable that underpins the experience of learning (Antonacopoulou, 2014) and propels the Courage to relinquish control; the Commitment to learn; the Confidence to let go of existing knowedge; and the Curiosity to keep searching, even if it means becoming a perpetual and vulnerable beginner.

Making the case for sensoriality as a new paradigm in future management and organisational learning research and practice extends our analysis and treatment of learning as work in progress and presents more clearly the impact of Sensuous Learning as a response to the Volatility, Uncertainty, Complexity and Ambiguity (VUCA, Bennett \& Lemoine, 2014) that characterise the $21^{\text {st }}$ Century. Understanding such VUCA conditions is imperative in explicating how Sensuous Learning can be operationalised to advance Sensuous Organizational Learning (Antonacopoulou, 2018b). In other words, VUCA conditions signal the crisis in learning so critical to make possible navigating and leading through such conditions. Johansen (2012) provides a response to this call for addressing the VUCA conditions with a 'VUCA Primer' as a mode of leading through VUCA conditions. For Johansen in order to respond to Volatility there is a need for Vision, Uncertainty calls for Understanding, Complexity calls for Clarity and Ambiguity calls for Agility.

Based on our analysis here and the proposed Sensuous Learning approach we advance here, we would argue that there is a space in-between conditions and responses that reflect the ways of leading which could support the learning essential to make such responses possible. In other words, if we advance new ways of learning for VUCA we need to also advance new ways of leading as marks of the choice to learn with a difference (Deleuze, 1994). It could be argued that Sensuous Learning can support ways of leading that enable Volatility to be met with Vision, when learning to feel safe being Vulnerable. In order to respond to Uncertainty, to form an accurate Understanding, calls for courage to remain Unnerved by the unknown. To respond to Complexity through Clarity calls for Candour. To embrace Ambiguity through Agility calls for Awakening. Recognising Vulnerability, Unnerved, Candour and Awakening as integral to sensoriality promotes a mode of learning leadership with VUCA for VUCA. We elaborate this approach of VUCA Learning Leadership as a way of reviving the idea of the 'New Learning Organisation'.

\section{VUCA Learning Leadership: The New Learning Organisation}

If we are to advance a new theory of learning that presents a new avenue in organisational learning research, we need to do so by duly recognising the foundations from 
which we can rebuild the ideal of the 'learning organisation' that Senge (2014) promised, but was not fully realized (Elkjaer, 2001). Daly and Overton (2017: 7) argue for 'the clarity of purpose' that necessarily must drive the 'New Learning Organisation', coupled with 'a shared vision and an open dialogue in how people are valued and need to adapt to deliver the organisation's performance' as they suggest. Similarly, driving the New Learning Organisation is rightfully about 'holistic people experience', 'thriving ecosystem', 'agile digitally enabled infrastructure', 'intelligent decision making' and 'continual engagement' (Daly \& Overton, 2017: 8-9) that are seen to form the expanded dimensions of Senge's (2014) earlier framing of the Learning Organisation. However, valuable as these dimensions are, they are still unlikely to attend to learning that serves the common good.

To serve the common good is essentially what VUCA conditions call for. This necessitates explicating how the Sensuous Learning discussed in the previous section can be supported through ways of leading as part of everyday life. This ontological extension to the concept of leadership places 'leading' beyond formal hierarchies, rank and privilege where political dignitaries, top managers, religious figures, and charismatic champions of one cause or another are to be found (Tourish, 2013). Antonacopoulou and Bento (2010, 2016) encourage us to look for leadership in another place, 'the context of the ordinary people' who find in themselves, and in others, a different place from which to act in 'extraordinary' ways to serve the common good. Perhaps the most fundamental aspect of such an ontological stance is not only the acts of ordinary people, that can account as leadership practice. It is also the way ordinary people become the place that matters, because they exist in a place - they are at home (become mature humans). This point has profound implications in our conceptualisation of leadership beyond its enactment and embodiment but in its emplacement. In this sense, 'leadership is not a place where suffering is avoided or courage is unnecessary' (Adler \& Delbecq, 2017: 11). Emplaced leadership is learning leadership because it calls for courage, commitment, confidence and curiosity to persevere, because discovering compassion is where the love for life and freedom are realised (Antonacopoulou \& Bento, 2018). Leadership charged with Sensuous Learning becomes dynamic, collective, relational, as well as reflexive (Alvesson et al., 2017) that is situated and socially defined, and where practising receives special consideration. Sensuous Learning itself is sustainable not because it is performed by 'learning leaders' as Daly \& Overton, 2017: 39) suggest. Learning leaders are not only Learning and Development professionals. Learning leaders are all learners who choose to lead a life of learning. 
Antonacopoulou \& Bento (2003, 2010, 2016, 2018) have been advancing 'Learning leadership' on the basis of three characteristics: 'Leadership as a window to inner learning', as a 'relational process' and as a 'labour of love'. Leadership as a window to inner learning, fundamentally entails a search to discover one's true self, a leader's true voice in service of a higher purpose. This requires an activation of one's own learning, by setting the example in fostering the learning and growth of others. This kind of inner learning acknowledges leaders as profoundly human, who can see the humanity of others. Listening to their voice of conscience enables them to become individuals in the full sense of the word: both in terms of nurturing what individuates them from others - in the sense of their unique characteristics- but also in terms of being 'un-divided' - recognizing that they are 'an inseparable part of the social whole' (Antonacopoulou \& Bento, 2010: 100). This point reflects not only leadership as a relational process but also a way of relating to others in their own terms, in the individuality that their inner agility as a pathway to collectivity and connectivity. Inner agility supports human flourishing in fostering leadership as a relational process one where relating to others is orientated to serve the common good. This extends accounts of the distributed nature of leadership and positions leadership as a practice embedded in the dynamic social interactions that govern the ways practising leading reveal opportunities to make waves to fulfill 'leader-ship' as the platform - the ship - where multiple leaders can grow (Antonacopoulou, 2012). Leadership as a relational process not only 'recognizes the inherently polyphonic and heteroglossic nature of life' calling for engagement 'in relational dialogue' as Cunliffe and Eriksen (2011: 1425) suggest. It is also about becoming truly aware of the common humanity that unites individuals in forming communities to serve the common good. The sense of interconnectedness that governs Learning Leadership is reflected in the active membership in communities, where they step up as needed, but also have the humility and self-respect to recognize and celebrate the talents of others, acknowledging the leaderful capacity to learn in a given context, which may call for us to imagine instead that there are no 'leaders', as Raelin (2016) suggests.

This is where Leadership as a labour of love, rooted in phronesis (Antonacopoulou \& Bento, 2016) becomes the 'generative process of growing one's identity when one fully joins society' (Antonacopoulou \& Bento, 2010: 77). Learning leadership can be seen not as a goal in and of itself, but as the natural consequence of doing something one loves, surrendering to everyday experience as a central source of learning and becoming a leader by virtue of one's response to such experience. This is why as a 'labour' - a persistent effort 
of everyday experience, Learning Leadership is phronetic, because it is through practising leading within a given community and context, that learning leaders build insights from the choices they make, exercising practical judgment as they formulate intentions and choose courses of action that serve a higher purpose as opposed to self-interest. This recursive process in the search for higher purpose becomes the road to leadership because as a labour of love, the choice to conduct oneself with phronesis creates the potential for a generative experience of becoming fully human. Through the practical judgments leaders exercise in the everyday choices they make, they become learning conduits. In this respect, the conduct of learning leaders becomes the conductor energizing the learning and leadership that mobilises serving the common good.

Leadership conceptualized in these terms, presents a fresh ontological stance to what leadership means. It offers a foundation for conceptualising Sensuous Leadership as a process of connecting ways of knowing and acting integral to Sensuous Organisational Learning and mobilising the 'New Learning Organisation' with and through sensoriality. Through sensoriality VUCA Learning Leadership enables learning to feel safe being Vulnerable; learning to remain Unnerved by the unknown, learning to demonstrate Candour and learning to experience Awakening as impactful learning. These VUCA Learning Leadership dimensions are integral aspects of the new paradigm in Organisational and Management Learning research focusing on emplacement as a way of appreciating the role of sensuousness in living, working, organizing and above all learning. This mode of Learning Leadership is presented here as a platform for developing the 'New Learning Organisation' because, it invites going beyond the sensory appreciation to also understand this kind of contagious learning which enables leaders to be 'willing to feel the vulnerability implicit in not knowing' (Antonacopoulou \& Bento, 2003: 83) demonstrating the courage to 'see reality as it is' and 'inspire people to move from current reality, back to possibility' (Adler, 2011: 211, 215).

\section{Discussion and Conclusions}

In this paper we set out a vision for future management and organisational learning research focusing on emplacement as a new paradigm that can inform both how the process and practice of learning may be understood and supported beyond the work-place. Our concern non-the-less remains the individual and collective growth and maturity, as one of 
the key impacts of learning and for that reason we made the case expending our focus on socio-material conditions that affect what, how and why learning may or may not take place. In this respect we expanded the conceptualisation of learning in relation to cognitive and emotional processes, knowledge acquisition and behavioural change. We made the case for sensoriality as a way of embracing not knowing.

Navigating the unknown reflects the essence of organisational and management learning in the $21^{\text {st }}$ century. This is because, Volatility, Uncertainty, Complexity and Ambiguity (VUCA) make existing knowledge insufficient to address the crisis in learning that otherwise the unknown creates. To support the capacity for ways of knowing and acting to respond to VUCA conditions necessitates new modes of learning - Learning-in-Crisis (Antonacopoulou \& Sheaffer, 2014) that enable making sense beyond cognitions and emotions but also through sensations. The alignment of sensibility, sensitivity and sentience explicates the new theory of learning presented here as Sensuous Learning inspiring Sensuous Organisational Learning through Sensuous Leadership (Antonacopoulou, 2018a; 2018b).

The uniqueness of Sensuous Learning compared to previous accounts of sensory knowing is that the focus extends beyond orchestrating the senses. It introduces sensoriality as a way of leading where practical judgements are formed reflexively to embrace conditions that call for curiosity, confidence, courage and commitment to serve the common good. These qualities of Learning Leadership signal that VUCA conditions can be met with Vision, Understanding, Clarity and Agilty as Johansen (2012) suggests. However, they do not explain how the learning that can support such a response may be possible. Here is where sensoriality is employed to suggest a mode of VUCA Learning Leadership that extends, beyond relationality, inner learning and acting as a conduit for others' learning as Antonacopoulou and Bento (2010; 2018) suggest. Sensoriality introduces a VUCA approach to Learning Leadership which emphasises Vulnerabiity as a condition for safety to act with good judgement, being Unnerved as a mark of strength of character in extending beyond current levels of competence, to practise possibilities with Candour in the openness and flexibility that not knowing the outcome demands. Hence, also why a sense of Awakening that enables Agility to emerge due to the capacity to use practical judgement to anticipate the consequences of one's actions before and whilst acting, signalling that sensoriality prompts greater Attentiveness, Alertness, Awareness and Apprecation of the impact of VUCA conditions (Antonacopoulou, 2018b). 
In short, promoting through Sensuous Organisational Learning the possibility for the New Learning Organisation, we go beyond conditions and measures to navigate the unknown. We refresh the strategic role of learning to reconstruct the reality that is lived by the people who create the VUCA conditions and in doing so to build the maturity through VUCA Learning Leadership to reach the VUCA Premier state. Central to this sensoriality of using VUCA for VUCA is the sustainability of VUCA as a mark of the general movement and shift that the $21^{\text {st }}$ Century discloses. Such disclosure as we have explicated goes beyond making sense retrospectively or prospectively, cognitively or emotionally. It calls for sensing and not knowing the outcome but striving for the impact of learning. By committing to practising as a means of improving actions, the emerging ways of leading restore not only meaningfulness in learning, but also in living, working and organizing. In this respect, the common good stands a better chance of being served when practical judgements are formed founded on another intelligence. Analytical and mental capability (as marks of IQ) and empathy and compassion aptitude (as marks of EQ emotional intelligence) do not suffice. Sensoriality cultivates a new CORE Intelligence (CQ) that enables learners to remain centred on who they chose to become as humans, experiencing oneness with the ecosystem they contribute in creating, reflexive in their capacity to use phronesis to guide their energy to do the right thing (Antonacopoulou, 2018a).

This new learning theory offers the scope to radically rethink the way leaning is supported in organisations and to renew analytically and in empirical terms how to foster and study movements beyond what is visible toward that which is sensed. The sensations that are felt can act as vibrations energizing innovative modes of learning, knowing, leading and acting beyond aesthetic means. Arts-based methods and interventions will remain an important area to continue to investigate and support in organisations, akin to major organisational transformation initiatives, like 'Catalyst' in Unilever. Indeed, many of the interventions internationally captured in the work of the GNOSIS 2020 network (see Antonacopoulou \& Taylor, 2018b) show that there is great scope to support individual and collective growth through Arts-Based Interventions, because they have the power to instigate collective leadership and transformation. 




Figure 1: Sensoriality - Learning, Leading, Acting, Knowing with VUCA for VUCA

However, there are also important methodological opportunities to expand the 'strong' process perspective that goes beyond capturing movement as a change from one state to another, described as arrows between boxes (Feldman, 2016). Instead, there is scope to explore the oscillation effects when what we can call micro-movements - sensations foster continuous 'becoming' (Langley et al., 2013). As we have sought to show in this analysis it is possible to use the same conditions to identify the responses necessary and the learning that can mobilise the ongoing movement. We showed, VUCA conditions calling for VUCA responses (primer) and VUCA Learning Leadership. We capture this diagrammatically in Figure 1 to suggest that the oscillations reflect a movement of back and forth as sensoriality, along with socio-materiality and an active emplacement in the ecosystem co-created guide the pace with which such movement unfolds. This is not only a generative dance as the opportunity to capture such movement demands going beyond 
traditional ways of making sense. The retrospective enactment of growth and maturation will not do justice to the emerging prospective possibilities born with greater emotional engagement in the process of sensing what feels right as a way of organising and responding to the changing conditions. An emplaced orientation to making sense also makes a new place from which to draw ideas on how to create possibilities. This is why we propose that central to Sensuous Learning and the New Learning Organisation lies a new form of intelligence one that lies at the CORE of what it means to be human. We hope that this inspires the development of a more humanist approach to learning, managing and organising; one that demonstrates the capacity for phronesis to serve the common good. 


\section{References}

Adler, N.J. \& Delbecq, A. L. (2017). Twenty-First Century Leadership: A Return to Beauty. Journal of Management Inquiry, 27(2), 119-137

Adler, N.J. (2011). Leading Beautifully. The Creative Economy and Beyond. Journal of Management Inquiry. 20: 208-221

Alvesson, M. Blom M. and Sveningson, S. (2017). Reflexive Leadership: Organizing in an Imperfect World. London: Sage.

Antonacopoulou, E.P. (2004). On the Virtues of Practising Scholarship: A Tribute to Chris Argyris a 'Timeless Learner'. Management Learning, 35(4), 381-395

Antonacopoulou, E.P. (2006). The Relationship between Individual and Organisational Learning: New Evidence from Managerial Learning Practices, Management Learning, $37(4), 455-473$.

Antonacopoulou, E.P. (2008). On the Practise of Practice: In-tensions and ex-tensions in the ongoing reconfiguration of practice. In D. Barry and H. Hansen (Eds.). Handbook of New Approaches to Organization Studies, (pp. 112-131). London: Sage.

Antonacopoulou, E.P. (2010a). Beyond Co-production: Practice-Relevant Scholarship as a Foundation for Delivering Impact Through Powerful Ideas, Public Money and Management 30(4), 219-225.

Antonacopoulou, E.P. (2010b). Making the Business School More 'Critical': Reflexive Critique based on Phronesis as a Foundation for Impact. British Journal of Management. $21,6-25$.

Antonacopoulou, E.P. (2012). Leader-ship: Making Waves. In Owen, H. (Ed.). New Insights into Leadership: An International Perspective, (pp. 47-66). London: Kogan Page.

Antonacopoulou, E.P. (2014). The Experience of Learning in Space and Time. Prometheus. 32(1), 83-91. 
Antonacopoulou, E.P. (2015). One more time - What is Practice? Teoria e Práctice em Administração (Theory and Practice Management Journal - Leading Brazilian Journal), $5(1), 1-26$

Antonacopoulou, E.P. (2017). The Capacity for Phronesis: Building Confidence through Curiosity to cultivate Conscience as central to the Character of Impactful Research. In Bartunek, J \& McKenzie, J. (Eds.). Academic Practitioner Research Partnerships: Development, Complexities and Opportunities. 160-178. London: Routledge.

Antonacopoulou, E.P. (2018a). Sensuous Learning: What is it and Why it Matters in addressing the Ineptitude in Professional Practice. In E.P. Antonacopoulou \& S.S. Taylor, (Eds.). Sensuous Learning for Practical Judgment in Professional Practice: Volume 1: Arts-based Methods. Chapter 2. London: Palgrave Macmillan.

Antonacopoulou, E.P. (2018b) Sensuous Learning for Individuals, Communities and Organisations. In E.P. Antonacopoulou \& S.S. Taylor, (Eds.). Sensuous Learning for Practical Judgment in Professional Practice: Volume 2: Arts-based Interventions. London: Chapter 2. Palgrave Macmillan.

Antonacopoulou, E.P. \& Bento R. (2003). Methods of 'learning leadership': Taught and experiential. In Storey, J. (Ed.). Current Issues in Leadership and Management Development, (pp. 71-92) Oxford: Blackwell.

Antonacopoulou, E.P. \& Bento, R. (2010). Learning leadership in practice. In Storey, J. (Ed.). Leadership in Organizations: Current Issues and Key Trends. (2. ed.) (pp. 81-102). London: Routledge

Antonacopoulou, E.P. \& Bento, R. (2016). Learning leadership: A call to beauty. In Storey, J. (Ed.). Leadership in Organizations: Current Issues and Key Trends. (3. ed.) (pp. 99112). London: Routledge.

Antonacopoulou, E.P. \& Bento, R. (2018). From Laurels to Learning: Leadership with Virtue, Journal of Management Development, Special Issue. Forthcoming

Antonacopoulou, E.P. \& Chiva, R. (2007). The Social Complexity of Organizational Learning: Dynamics of Learning and Organising, Special Issue. Management Learning, 38(3), 277-296 
Antonacopoulou, E.P. \& Sheaffer, Z. (2014). Learning in Crisis: Rethinking the Relationship between Organizational Learning and Crisis Management. Journal of Management Inquiry, 23(1), 5-21

Antonacopoulou, E.P. \& Taylor, S. (2018a). Sensuous Learning for Practical Judgment in Professional Practice: Volume 1: Arts-based Methods. London: Palgrave Macmillan

Antonacopoulou, E.P. \& Taylor, S. (2018b). Sensuous Learning for Practical Judgment in Professional Practice: Volume 2: Arts-based Interventions. London: Palgrave Macmillan

Argyris, C. (1957). The Individual and Organization: Some Problems of Mutual Adjustment. Administrative Science Quarterly, 2(1), 1-24.

Argyris, C. (2003). A Life Full of Learning. Organization Studies. 24(7),1178-1192.

Argyris, C., Putnam, R., \& Smith, D. M. (1985). Action science: Concepts, methods, and skills for research and intervention. San Francisco, CA: Jossey-Bass.

Bennett, N. \& Lemoine G.J. (2014). What a difference a word makes: Understanding threats to performance in a VUCA world, Business Horizons, 57 (3), 311 -317.

Berthoin Antal, A. (2014). When arts enter organizational spaces: Implications for organizational learning. In P. Meusburger, A. Berthoin Antal and L. Suarsana (Eds.). Knowledge and Space. Learning Organizations: Extending the Field. 177-201. Dordrecht, Netherlands: Springer.

Berthoin Antal, A., Dubucquet G. \& Fremeaux, S. (2018). Meaningful work and artistic interventions in organizations: Conceptual development and empirical exploration. Journal of Business Research, 85, 375-385.

Bourdieu P. (1990). The Logic of Practice. Cambridge: Polity

Carlile, P., Nicolini, D., Langley, A. \& Tsoukas, H. (2013). How matter matters: Objects, artifacts and materiality in organization studies. In Carlile P, Nicolini D, Langley A and Tsoukas H (Eds.). How Matter Matters: Objects, Artifacts and Materiality in Organization Studies. Oxford, UK: Oxford University Press, 1-15. 
Casey, A. (2005). Enhancing individual and organizational learning-A sociological model. Management Learning, 36, 131-147

Clegg, S. R., Kornberger, M., \& Rhodes, C. (2005). Learning/becoming/organizing. Organization, 12, 147-167

Coghlan, D. \& Brannick, T. (2014). Doing action research in your own organization. (4. ed.). London: Sage.

Crossan, M., Byrne, A., Seijts, G., Reno, M. Monzani, L. \& Gandz, J. (2017) Toward a Framework of Leader Character in Organizations. Journal of Management Studies. 54(7), 986-1018.

Crossan, M.M., Maurer, C.C. \& White, R.E. (2011). Reflection on the2009 AMR Decade Award: Do we have a Theory of Organizational Learning? Academy of Management Review. 36, 446-460.

Cunliffe, A.L. \& Eriksen, M. (2011). Relational leadership. Human Relations, 64(11), 14251449

Daly, J. \& Overton, L. (2017). Driving the New Learning Organization: How to unlock the potential of Learning and Development, CIPD and Toward Maturity. www.towardsmaturity.org/learningorg2017

Deleuze, G. (1994). Difference and Repetition, London: Continuum.

Elkjaer B., (2001). 'The Learning Organization: An Undelivered Promise', Management Learning, 32(4), 437-452

Feldman, M.S. (2016). Making process visible: Alternatives to boxes and arrows. In: Langley, A. and Tsoukas, H. (Eds.). The SAGE Handbook of Process Organization Studies. 625635. London: Sage.

Gherardi, S. (2015). To start theorising practice anew: The contribution of concepts of agencement and formativeness. Organisation, 23(5), 680 - 698

Greenwood, D. J. \& Levin, M. (2007). Introduction to Action Research: Social Research for Social Change, $2^{\text {nd }}$ ed. Thousand Oaks: Sage. 
Havard, A. (2014). Virtuous Leadership: An Agenda for Personal Excellence. Scepter: USA

Hedberg, B. (1981). How organizations learn and unlearn. In P. Nystrom \& W. H. Starbuck (Eds.). Handbook of organizational design, (pp. 3-27). Oxford University Press, NY.

Ingold, T. (2000) The Perception of the Environment. London: Routledge

Johansen, B. (2012). Leaders Make the Future: Te New Leadership Skills. Berrett-Koehler: SF California.

Langley, A. \& Tsoukas, H. (2016). Introduction. In Langley, A. and Tsoukas, H. (Eds.). The SAGE Handbook of Process Organization Studies. London: Sage, 1-25.

Langley, A., Smallman, C., Tsoukas, H. \& Van de Ven, A.H. (2013). Process studies of change in organization and management: Unveiling temporality, activity, and flow. Academy of Management Journal 56(1), 1-13.

MacIntyre, A., (1985). After Virtue: A Study in Moral Theory. London: Duckworth.

Maitlis, S. \& Christianson, M. (2014). Sensemaking in Organizations: Taking Stock and Moving Forward. The Academy of Management Annals 8(1), 57-125

Merleau-Ponty, M. (1962). Phenomenology of Perception London: Routledge and Kegan Paul

Orlikowski, W.J. \& Scott, S.V. (2008). Sociomateriality: Challenging the separation of technology, work and organization. The Academy of Management Annals 2(1), 433-474.

Panayiotou, A. (2017) Introduction to the Virtual Special Issue on Sensory Knowledge. Management Learning. Retrieved from http://journals.sagepub.com/page/mlq/collections/virtual-specialissues/sensory_knowledge?pbEditor=true (Accessed July 2018).

Pareyson L. (1960). Estetica: teoria della formatività. Bologna: Zanichelli.

Pink, S. (2011). From embodiment to emplacement: Re-thinking competing bodies, senses and spatialities. Sport, Education and Society 16 (3), 343-55. 
Raelin, J.A., (2016). Imagine there are no leaders: Reframing Leadership as collaborative agency. Leadership. 12(2), 131-158.

Romanowska, J., Larsson, G. \& Theorell, T., (2013), "Effects on leaders of an art-based leadership intervention,” Journal of Management Development, 32(9), pp.1004-1022.

Ropo, A., Salovaara, P., Sauer, E. \& De Paoli, D. (Eds.). (2015) Leadership in Spaces and Places. Cheltenham, UK and Northampton, MA: Edward Elgar.

Senge, P. M. (2014). The Fifth Discipline: The Art \& Practice of the Learning Organization. New York: Doubleday.

Serres, M. (1995). Genesis, Michigan: University of Michigan Press.

Shotter, J. \& Tsoukas, H. (2014a). Performing Phronesis: On the Way to Engaged Judgment. Management Learning, 45(5), 377-396

Shotter, J. \& Tsoukas, H. (2014b). In search of Phronesis: Leadership and the art of judgment. Academy of Management Learning and Education, 13, 224-243.

Shove, E, M. Pantzar, \& M. Watson. (2012). The dynamics of social practice: Everyday life and how it changes. London: SAGE.

Spinosa, C., Flores, F. \& Dreyfus, H. L. (1997). Disclosing New Worlds. Entrepreneurship, Democratic Action and the Cultivation of Solidarity Cambridge, MA: MIT Press.

Springborg, C. (2018). Sensory templates and manager cognition: Art, cognitive science and spirtual practice in management education. London: Palgrave Macmillan.

Strati A (2007). Sensible knowledge and practice-based learning. Management Learning $38,61-77$.

Taylor, S., \& Ladkin, D. (2009). Understanding Arts-Based Methods in managerial development. Academy of Management Learning and Education, 8(1), 55-69.

Taylor, S.S. (2015). You're a Genius. Using Reflective Practice to Master the Craft of Leadership. NY: Business Expert Press 
Tourish, D. (2013). The dark side of transformational leadership: A critical perspective. London: Routledge.

Weick KE (2010). Reflections on enacted sensemaking in the Bhopal disaster. Journal of Management Studies, 47(3), 537-550. 